\title{
Low serum total testosterone level as a predictor of upstaging and upgrading in low-risk prostate cancer patients meeting the inclusion criteria for active surveillance
}

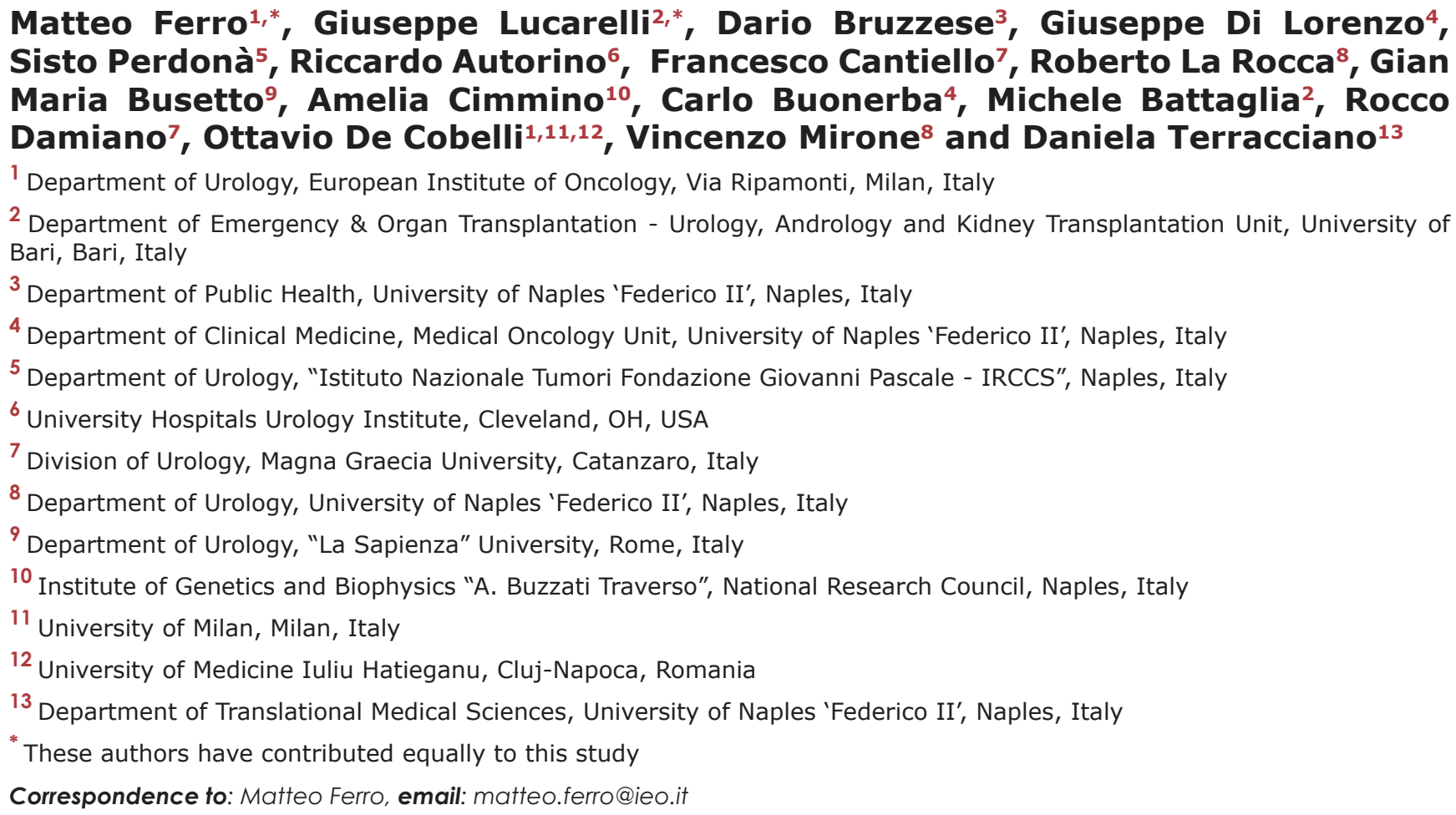
Sisto Perdonà ${ }^{5}$, Riccardo Autorino ${ }^{6}$, Francesco Cantiello ${ }^{7}$, Roberto La Rocca ${ }^{8}$, Gian Maria Busetto ${ }^{9}$, Amelia Cimmino ${ }^{10}$, Carlo Buonerba ${ }^{4}$, Michele Battaglia ${ }^{2}$, Rocco Damiano ${ }^{7}$, Ottavio De Cobelli ${ }^{1,11,12}$, Vincenzo Mirone ${ }^{8}$ and Daniela Terracciano ${ }^{13}$

${ }^{1}$ Department of Urology, European Institute of Oncology, Via Ripamonti, Milan, Italy

${ }^{2}$ Department of Emergency \& Organ Transplantation - Urology, Andrology and Kidney Transplantation Unit, University of Bari, Bari, Italy

${ }^{3}$ Department of Public Health, University of Naples 'Federico II', Naples, Italy

${ }^{4}$ Department of Clinical Medicine, Medical Oncology Unit, University of Naples 'Federico II', Naples, Italy

${ }^{5}$ Department of Urology, "Istituto Nazionale Tumori Fondazione Giovanni Pascale - IRCCS", Naples, Italy

${ }^{6}$ University Hospitals Urology Institute, Cleveland, $\mathrm{OH}$, USA

7 Division of Urology, Magna Graecia University, Catanzaro, Italy

8 Department of Urology, University of Naples 'Federico II', Naples, Italy

9 Department of Urology, "La Sapienza" University, Rome, Italy

${ }^{10}$ Institute of Genetics and Biophysics "A. Buzzati Traverso", National Research Council, Naples, Italy

${ }^{11}$ University of Milan, Milan, Italy

12 University of Medicine Iuliu Hatieganu, Cluj-Napoca, Romania

13 Department of Translational Medical Sciences, University of Naples 'Federico II', Naples, Italy

${ }^{*}$ These authors have contributed equally to this study

Correspondence to: Matteo Ferro, email: matteo.ferro@ieo.it

Giuseppe Lucarelli, email: giuseppe.lucarelli@inwind.it

Amelia Cimmino, email: amelia.cimmino@igb.cnr.it

Keywords: testosterone, prostate cancer, active surveillance, upgrading, upstaging

Received: June 13,2016 Accepted: October 14, $2016 \quad$ Published: October 25, 2016

\section{ABSTRACT}

Active surveillance (AS) is currently a widely accepted treatment option for men with clinically localized prostate cancer (PCa). Several reports have highlighted the association of low serum testosterone levels with high-grade, high-stage PCa. However, the impact of serum testosterone as a predictor of progression in men with low-risk PCa has been little assessed.

In this study, we evaluated the association of circulating testosterone concentrations with a staging/grading reclassification in a cohort of low-risk PCa patients meeting the inclusion criteria for the AS protocol but opting for radical prostatectomy.

Radical prostatectomy (RP) was performed in 338 patients, eligible for AS according to the following criteria: clinical stage T2a or less, PSA $<10 \mathrm{ng} / \mathrm{ml}$, two or fewer cancer cores, Gleason score (GS) $\leq 6$ and PSA density $<0.2 \mathrm{ng} / \mathrm{mL} / \mathrm{cc}$. Reclassification was defined as upstaging (stage>pT2) and upgrading (GS $\geq 7$; primary Gleason pattern 4) disease. Unfavorable disease was defined as the occurrence of pathological stage >pT2 and predominant Gleason score 4. Total testosterone was measured before surgery. 
Low serum testosterone levels ( $<300 \mathrm{ng} / \mathrm{dL}$ ) were significantly associated with upgrading, upstaging, unfavorable disease and positive surgical margins. The addition of testosterone to a base model, including age, PSA, PSA density, clinical stage and positive cancer involvement in cores, showed a significant independent influence of this variable on upstaging, upgrading and unfavorable disease.

In conclusion, our results support the idea that total testosterone should be a selection criterion for inclusion of low-risk PCa patients in AS programs and suggest that testosterone level less than $300 \mathrm{ng} / \mathrm{dL}$ should be considered a discouraging factor when a close AS program is considered as treatment option

\section{INTRODUCTION}

Active surveillance (AS) has recently emerged as an alternative treatment for patients with lowrisk prostate cancer $(\mathrm{PCa})$-related mortality, whereby curative intervention can be delayed until the time that disease is re-classified or there is evidence of disease progression [1]. At present, urologists still suffer from a limited preoperative ability to reliably predict the tumor aggressiveness. Clinical stage, tumor grade (biopsy Gleason score) and prostate-specific antigen (PSA) are the established preoperative prognostic markers. However, despite these variables it is still difficult to determine which patients are candidates for AS. Literature data indicate a progression rate of about $30 \%$ in men on AS and a PCa-specific survival of $<97 \%$ at 5 years [2]. Thus, there is an urgent need of additional markers allowing us to discriminate between indolent or aggressive diseases.

Accumulating data indicate an important association between low testosterone concentrations and worrisome aspects of PCa. Multiple studies have reported the association of lower serum testosterone concentrations with high-grade $\mathrm{PCa}$ and a higher stage at presentation [3-6]. Furthermore, there is growing evidence supporting the theory that a drop in serum testosterone levels may modulate PCa risk and aggressiveness, since different metabolic disorders, such as obesity and metabolic syndrome (MetS), which are associated with low serum testosterone levels, have also been associated with an unfavorable PCa outcome $[7,8]$.

On this basis, total testosterone should be measured in patients with a localized $\mathrm{PCa}$, in particularly when $\mathrm{AS}$ or nerve-sparing surgery is considered. In this study, we explored the impact of serum testosterone on upgrading, upstaging, unfavorable disease, positive surgical margins and predominant Gleason score 4 in a cohort of patients with very low-risk PCa who met the inclusion criteria for Prostate Cancer Research International: Active Surveillance (PRIAS) protocol, but elected to undergo radical prostatectomy $(\mathrm{RP})$.

\section{RESULTS}

A total of 338 patients with PCa were enrolled in this study. Demographic and clinical characteristics of the overall study population are summarized in Table 1.

Total testosterone levels showed a significant association with all the main outcomes of interest (table 2). In particular, when treated as a continuous variable, lower total testosterone levels (median [IQR]) were associated with reclassification in terms of upstaging (299.5 [250; 390] vs. $488.5[401 ; 600] ; p<0.001)$, upgrading (400.5 [292.25; 534] vs. 497.5 [401; 600]; $p<0.001)$, unfavorable disease $(290[250 ; 300] v s .456$ $[390 ; 567] ; p<0.001)$ and predominant Gleason score 4 (300 [254; 502] vs. 477 [398; 597]; $p<0.001)$. These associations were confirmed when subjects were analysed according to the presence or absence of a hypogonadism condition (total testosterone $<300 \mathrm{ng} / \mathrm{dL}$ ). In addition, we found a significantly higher rate of hypogonadism in PCa patients with positive surgical margins $(27.8 \%$ vs. $14.2 \% ; p=0.035$ ). Of note, cancer involvement in positive cores (CIPC) was also significantly associated with all the outcomes (Table 2a and 2b). Receiver Operating Characteristic (ROC) curve analysis supported the prognostic role of total testosterone in the reclassification of men on AS (Figures 1-4). The corresponding area under the curve (AUC) ranged from 0.66 (95\% C.I. 0.60 to 0.72 ) for upgrading, to 0.81 (95\% C.I. 0.75 to 0.88 ) for upstaging. Sensitivities and specificities of total

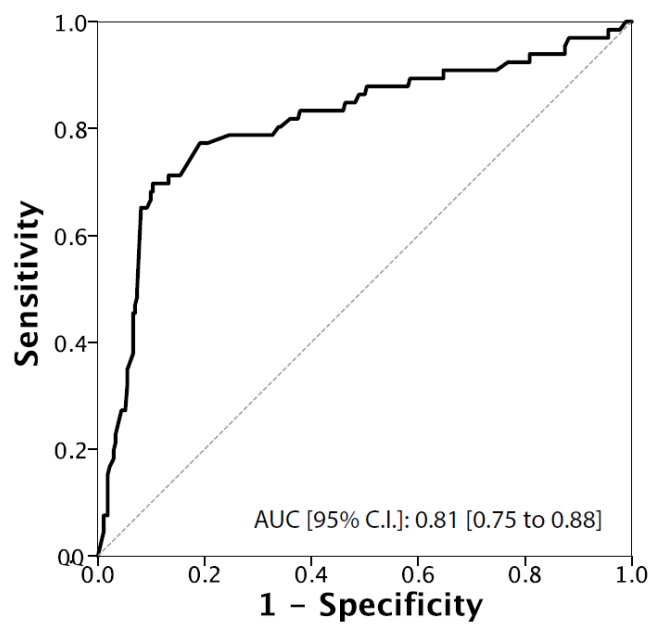

Figure 1: ROC Curve analysis for testosterone as a predictor of upstaging 
Table 1: Clinical and Pathological Characteristics.

\begin{tabular}{|l|l|}
\hline Variable & $\begin{array}{l}\mathbf{n}=\mathbf{3 3 8} \\
\text { Median }\left[\mathbf{2 5}^{\text {th }}-\mathbf{7 5}^{\text {th }} \text { percentile] }\right.\end{array}$ \\
\hline Age, years & $63.5[59 ; 67]$ \\
\hline PSA (ng/mL) & $5.6[4.29 ; 7.25]$ \\
\hline PSA density & $0.12[0.09 ; 0.15]$ \\
\hline Prostate Volume & $49[40.75 ; 55]$ \\
\hline Familiarity, Yes & $21(6.2 \%)$ \\
\hline PNI, Yes & $20(5.9 \%)$ \\
\hline Nr of Positive Cores, 2 & $160(47.3 \%)$ \\
\hline Max $\%$ of core involved by tumor & $20[10 ; 30]$ \\
\hline Positive DRE & $36(10.7 \%)$ \\
\hline Testosterone (ng/dL) & $451.5[380 ; 566]$ \\
\hline Testosterone $<300 n g / d L$ & $53(15.7 \%)$ \\
\hline
\end{tabular}

PNI, perineural invasion.

Table 2a: Clinical and pathological variables associated with tumor upstaging and upgrading. CIPC: cancer involvement in positive cores.

\begin{tabular}{|c|c|c|c|c|c|c|}
\hline & \multicolumn{2}{|l|}{ Upstaging } & \multirow[b]{2}{*}{$p$-value } & \multicolumn{2}{|l|}{ Upgrading } & \multirow[b]{2}{*}{$p$-value } \\
\hline & No $(n=272)$ & Yes $(n=66)$ & & No $(n=192)$ & Yes $(n=146)$ & \\
\hline Age (years) & $63.5[59 ; 67]$ & $63.5[58.75 ; 66]$ & 0.918 & $63[58 ; 67]$ & $64[59.75 ; 67]$ & 0.176 \\
\hline PSA (ng/mL) & $5.68[4.35 ; 7.3]$ & $5.6[4.12 ; 6.68]$ & 0.584 & $5.55[4.2 ; 7.3]$ & $5.6[4.43 ; 7.09]$ & 0.834 \\
\hline PSA density & $0.12[0.09 ; 0.15]$ & $0.12[0.09 ; 0.15]$ & 0.716 & $0.12[0.09 ; 0.15]$ & $0.12[0.09 ; 0.15]$ & 0.468 \\
\hline Prostate Volume & $48[40 ; 55]$ & $49.5[41 ; 54.25]$ & 0.728 & $49[41 ; 55]$ & $48.5[40 ; 55]$ & 0.681 \\
\hline Familiarity, Yes & $16(5.9)$ & $5(7.6)$ & 0.576 & $12(6.3)$ & $9(6.2)$ & 0.974 \\
\hline PNI. Yes & $13(4.8)$ & $7(10.6)$ & 0.083 & $7(3.6)$ & $13(8.9)$ & 0.042 \\
\hline Nr of Positive Cores, 2 & $122(44.9)$ & $38(57.6)$ & 0.063 & $86(44.8)$ & $74(50.7)$ & 0.282 \\
\hline CIPC $(\%)$ & $20[10 ; 30]$ & $40[30 ; 50]$ & $<0.001$ & $20[10 ; 30]$ & $30[20 ; 45]$ & $<0.001$ \\
\hline Positive DRE & $26(9.6)$ & $10(15.2)$ & 0.186 & $18(9.4)$ & $18(12.3)$ & 0.477 \\
\hline Testosterone (ng/dL) & $488.5[401 ; 600]$ & $299.5[250 ; 390]$ & $<0.001$ & $497.5[401 ; 600]$ & $400.5[292.25 ; 534]$ & $<0.001$ \\
\hline Testosterone $<300 \mathrm{ng} / \mathrm{dL}$ & $20(7.4)$ & $33(50)$ & $<0.001$ & $13(6.8)$ & $40(27.4)$ & $<0.001$ \\
\hline
\end{tabular}

DRE: Digital rectal examination; PNI: perineural invasion; PSA: prostate-specific antigen

testosterone for each of the outcomes and according to both the "best combination" cut-off point and the cut-off point denoting a condition of hypogonadism are reported in table $3 \mathrm{a}$ and $3 \mathrm{~b}$. To assess the role of total testosterone as an independent predictor of reclassification, a set of multivariable logistic regression models including age, PSA, PSA density, digital rectal examination (DRE) status and cancer involvement in positive cores (CIPC) was constructed (Table 4). Total testosterone included in these base models was a significant independent predictor, both as a continuous and dichotomous variable, of upstaging, upgrading and unfavorable disease. However, a significant gain in predictive accuracy was only detected for the outcome of upstaging (15.2\% when considering total testosterone as a continuous variable and $12.4 \%$ when treating total testosterone as a dichotomous variable) and predominant Gleason score $4(9.4 \%$ or $8.3 \%$, respectively). No advantages over the base model were observed for the outcome of upgrading, unfavourable disease and for the prediction of positive surgical margins.

\section{DISCUSSION}

The principal aim of an AS program is to reduce over-treatment in patients with clinically confined, 
Table 2b: Clinical and pathological variables associated with unfavorable disease, positive surgical margins and predominant Gleason score 4.

\begin{tabular}{|c|c|c|c|c|c|c|c|c|c|}
\hline & \multicolumn{2}{|c|}{ Unfavorable Disease } & \multirow[b]{2}{*}{$p$-value } & \multicolumn{2}{|l|}{ Positive margins } & \multirow[b]{2}{*}{$p$-value } & \multicolumn{2}{|c|}{ Predominant Gleason 4} & \multirow[b]{2}{*}{$p$-value } \\
\hline & No $(n=316)$ & Yes $(n=22)$ & & No $(n=302)$ & Yes $(n=36)$ & & No $(n=276)$ & Yes $(n=62)$ & \\
\hline Age (years) & $63.5[59 ; 67]$ & $63.5[59.5 ; 66]$ & 0,904 & $64[59 ; 67]$ & $61.5[55.5 ; 65]$ & 0.136 & $63[58 ; 67]$ & $64.5[60 ; 68]$ & 0,168 \\
\hline $\mathrm{PSA}(\mathrm{ng} / \mathrm{mL})$ & $5.6[4.4 ; 7.3]$ & $5.5[4 ; 6.3]$ & 0,244 & $5.64[4.29 ; 7.25]$ & $5.03[4.14 ; 7.27]$ & 0.451 & $5.6[4.4 ; 7.3]$ & $5.6[4.1 ; 7]$ & 0,43 \\
\hline PSA density & $0.12[0.09 ; 0.15]$ & $0.11[0.06 ; 0.14]$ & 0,068 & $0.12[0.09 ; 0.15]$ & $0.12[0.09 ; 0.15]$ & 0.925 & $0.12[0.09 ; 0.15]$ & $0.11[0.07 ; 0.15]$ & 0,073 \\
\hline Prostate Volume & $48[40 ; 55]$ & $52[41 ; 61.3]$ & 0,085 & $49[41 ; 55]$ & $45[38.5 ; 53.75]$ & 0.102 & $47.5[40 ; 55]$ & $51.5[41 ; 60]$ & 0,011 \\
\hline Familiarity, Yes & $20(6.3)$ & $1(4.5)$ & 1,000 & $19(6.3)$ & $2(5.6)$ & 1.000 & $17(6.2)$ & $4(6.5)$ & 1,000 \\
\hline PNI, Yes & $17(5.4)$ & $3(13.6)$ & 0,132 & $17(5.6)$ & $3(8.3)$ & 0.458 & $9(3.3)$ & $11(17.7)$ & $<0.001$ \\
\hline $\begin{array}{l}\mathrm{Nr} \text { of Positive Cores. } \\
\text {. }\end{array}$ & $146(46.2)$ & $14(63.6)$ & 0,123 & $146(48.3)$ & $14(38.9)$ & 0.283 & $129(46.7)$ & $31(50)$ & 0,642 \\
\hline CIPC (\%) & $25[10 ; 35]$ & $40[30 ; 60]$ & $<0.001$ & $25[10 ; 35]$ & $30[20 ; 40]$ & 0.027 & $20[10 ; 30]$ & $40[30 ; 50]$ & $<0.001$ \\
\hline Positive DRE & $32(10.1)$ & $4(18.2)$ & 0,273 & 32 (10.6) & $4(11.1)$ & 1.000 & $28(10.1)$ & $8(12.9)$ & 0,525 \\
\hline Testosterone (ng/dL) & $456[390 ; 567]$ & $290[250 ; 300]$ & $<0.001$ & $\left.\begin{array}{l}456 \\
566.25]\end{array}\right][389$ & $400.5[290 ; 540.5]$ & 0.0643 & 477 [398.3 ; 597.3] & $300[254.5 ; 502]$ & $<0.001$ \\
\hline $\begin{array}{l}\text { Testosterone }<300 \\
\mathrm{ng} / \mathrm{dL}\end{array}$ & 39 (12.3) & 14 (63.6) & $<0.001$ & $43(14.2)$ & $10(27.8)$ & 0.035 & $25(9.1)$ & $28(45.2)$ & $<0.001$ \\
\hline
\end{tabular}

CIPC: cancer involvement in positive cores; DRE: Digital rectal examination; PNI: perineural invasion; PSA: prostate-specific antigen

Table 3a: Sensitivities and specificities of total testosterone for each of the outcomes

\begin{tabular}{|l|l|l|l|}
\hline & Testosterone (ng/dL) & Sensitivity (95\% C.I.) & Specificity (95\% C.I.) \\
\hline Upstaging & 344 & $0.70(0.59$ to 0.8$)$ & $0.90(0.86$ to 0.93$)$ \\
\hline Upgrading & 431 & $0.60(0.52$ to 0.67$)$ & $0.70(0.63$ to 0.77$)$ \\
\hline Unfavorable disease & 302 & $0.85(0.81$ to 0.89$)$ & $0.82(0.64$ to 0.95$)$ \\
\hline Predominant Gleason 4 & 315 & $0.53(0.4$ to 0.66$)$ & $0.87(0.83$ to 0.91$)$ \\
\hline
\end{tabular}

Table 3b: Sensitivities and specificities of testosterone $<300 \mathrm{ng} / \mathrm{dL}$ (hypogonadism) for each of the outcomes

\begin{tabular}{|l|l|l|l|}
\hline & \multicolumn{2}{|l|}{ Hypogonadism condition } & Specificity (95\% C.I.) \\
\hline & Testosterone (ng/dL) & Sensitivity (95\% C.I.) & $0.92(0.89$ to 0.95$)$ \\
\hline Upstaging & 300 & $0.65(0.53$ to 0.76$)$ & $0.92(0.89$ to 0.96$)$ \\
\hline Upgrading & 300 & $0.34(0.27$ to 0.42$)$ & $0.82[0.64$ to 0.95$]$ \\
\hline Unfavorable disease & 300 & $0.85[0.81$ to 0.89$]$ & $0.88(0.84$ to 0.92$)$ \\
\hline Predominant Gleason 4 & 300 & $0.52(0.39$ to 0.65$)$ & \\
\hline
\end{tabular}

very-low-risk PCa, without compromising curative treatment [9]. The identification of these low risk PCa is still a critical issue today, and many markers have been identified for selecting candidates for non-aggressive therapies [10-16]. Although the selection criteria for AS include stringent clinicopathological parameters, it is well established that about a third of men on AS will undergo progression requiring active treatment $[1,17]$. Therefore, there is a strong interest in finding risk factors for reclassification and progression, particularly in men with a long life expectancy [18]. Conflicting results have been reported on the risk/benefit ratio of AS as upfront 
Table 4: Multivariable logistic regression models including age, PSA, PSA density, DRE status and CIPC for tumor upstaging, upgrading, unfavorable disease, positive surgical margins and predominant Gleason 4.

\begin{tabular}{|c|c|c|c|c|}
\hline & \multicolumn{4}{|l|}{ Upstaging } \\
\hline & Continous TT & & $\begin{array}{l}\text { TT } \geq 300 \mathrm{ng} / \mathrm{dL} \\
\mathrm{TT}<300 \mathrm{ng} / \mathrm{dL}\end{array}$ & \\
\hline & O.R. $[95 \%$ C.I.] & $p$-value & O.R. $[95 \%$ C.I. $]$ & $p$-value \\
\hline Age & $0.94[0.89$ to 1$]$ & 0,036 & $0.95[0.9$ to 1$]$ & 0,063 \\
\hline PSA (ng/mL) & $1.22[0.93$ to 1.6$]$ & 0,149 & $1.15[0.89$ to 1.5$]$ & 0,29 \\
\hline PSA Density, 0.1 increase & $0.47[0.14$ to 1.62$]$ & 0,231 & $0.45[0.13$ to 1.51$]$ & 0,193 \\
\hline Positive DRE & $1.31[0.48$ to 3.55$]$ & 0,600 & $1.14[0.42$ to 3.12$]$ & 0,798 \\
\hline CIPC & $1.05[1.03$ to 1.07$]$ & $<0.001$ & $1.05[1.03$ to 1.07$]$ & $<0.001$ \\
\hline Testosterone, $10 \mathrm{ng} / \mathrm{dl}$ increase & $0.92[0.89$ to 0.94$]$ & $<0.001$ & & \\
\hline Testosterone, $<300 \mathrm{ng} / \mathrm{dL}$ & & & $11.62[5.43$ to 24.85$]$ & $<0.001$ \\
\hline AUC, $[95 \%$ C.I. $]$ & $0.84[0.79$ to 0.9$]$ & & $0.81[0.75$ to 0.88$]$ & \\
\hline \multirow[t]{4}{*}{ Gain in predictive accuracy; \% (p-value) } & $15.2(<0.001)$ & & $12.4(0.002)$ & \\
\hline & \multicolumn{4}{|l|}{ Upgrading } \\
\hline & Continous TT & & 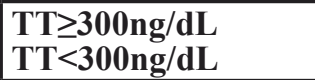 & \\
\hline & O.R. $[95 \%$ C.I.] & $p$-value & O.R. $[95 \%$ C.I.] & $p$-value \\
\hline Age & $1.01[0.96$ to 1.05$]$ & 0,827 & $1.01[0.96$ to 1.05$]$ & 0,791 \\
\hline PSA (ng/mL) & $1.02[0.84$ to 1.24$]$ & 0,868 & $1.02[0.83$ to 1.24$]$ & 0,87 \\
\hline PSA Density, 0.1 increase & $1.07[0.43$ to 2.63$]$ & 0,890 & $0.97[0.39$ to 2.39$]$ & 0,945 \\
\hline Positive DRE & $1.18[0.54$ to 2.6$]$ & 0,674 & $1.14[0.51$ to 2.53$]$ & 0,754 \\
\hline CIPC & $1.05[1.03$ to 1.07$]$ & $<0.001$ & $1.05[1.03$ to 1.07$]$ & $<0.001$ \\
\hline Testosterone, $10 \mathrm{ng} / \mathrm{dl}$ increase & 0.97 [0.96 to 0.99$]$ & 0,001 & & \\
\hline Testosterone, $<300 \mathrm{ng} / \mathrm{dL}$ & & & $3.6[1.74$ to 7.46$]$ & 0,001 \\
\hline AUC, $[95 \%$ C.I. $]$ & $0.73[0.68$ to 0.79$]$ & & $0.73[0.68$ to 0.79$]$ & \\
\hline \multirow[t]{4}{*}{ Gain in predictive accuracy; \% (p-value) } & $0.1(0.935)$ & & $0.1(0.922)$ & \\
\hline & \multicolumn{4}{|c|}{ Unfavorable Disease } \\
\hline & Continous TT & & $\begin{array}{l}\text { TT } \geq 300 \mathrm{ng} / \mathrm{dL} \\
\text { TT<300ng/dL }\end{array}$ & \\
\hline & O.R. [95\% C.I.] & $p$-value & O.R. [95\% C.I.] & $p$-value \\
\hline Age & $0.95[0.88$ to 1.03$]$ & 0,217 & $0.95[0.87$ to 1.03$]$ & 0,197 \\
\hline PSA (ng/mL) & 1.29 [0.86 to 1.93$]$ & 0,222 & $1.26[0.82$ to 1.92$]$ & 0,287 \\
\hline PSA Density, 0.1 increase & $0.14[0.02$ to 0.87$]$ & 0,035 & $0.12[0.02$ to 0.88$]$ & 0,037 \\
\hline Positive DRE & $1.23[0.34$ to 4.47$]$ & 0,754 & $1.03[0.27$ to 3.94$]$ & 0,968 \\
\hline CIPC & $1.05[1.02$ to 1.08$]$ & 0,001 & $1.05[1.02$ to 1.08$]$ & 0,002 \\
\hline Testosterone, $10 \mathrm{ng} / \mathrm{dl}$ increase & $0.93[0.89$ to 0.97$]$ & 0,001 & & \\
\hline Testosterone, $<300 \mathrm{ng} / \mathrm{dL}$ & & & $10.26[3.54$ to 29.76$]$ & $<0.001$ \\
\hline AUC, [95\% C.I.] & $0.84[0.77$ to 0.92$]$ & & $0.84[0.73$ to 0.95$]$ & \\
\hline Gain in predictive accuracy; \% (p-value) & $6.3(0.119)$ & & $5.9(0.101)$ & \\
\hline
\end{tabular}




\begin{tabular}{|c|c|c|c|c|}
\hline & \multicolumn{4}{|l|}{ Positive margins } \\
\hline & Continous TT & & \begin{tabular}{|l|} 
TT $\geq 300 \mathrm{ng} / \mathrm{dL}$ \\
TT $<300 \mathrm{ng} / \mathrm{dL}$
\end{tabular} & \\
\hline & O.R. [95\% C.I.] & $p$-value & O.R. [95\% C.I.] & $p$-value \\
\hline Age & $0.95[0.89$ to 1.01$]$ & 0,075 & $0.95[0.89$ to 1.01$]$ & 0,072 \\
\hline PSA (ng/mL) & $0.85[0.63$ to 1.15$]$ & 0,295 & $0.85[0.63$ to 1.14$]$ & 0,269 \\
\hline PSA Density, 0.1 increase & $1.85[0.5$ to 6.83$]$ & 0,358 & $1.79[0.49$ to 6.53$]$ & 0,379 \\
\hline Positive DRE & $0.85[0.26$ to 2.7$]$ & 0,776 & 0.84 [0.27 to 2.69$]$ & 0,774 \\
\hline CIPC & $1.02[0.99$ to 1.04$]$ & 0,191 & $1.02[0.99$ to 1.04$]$ & 0,205 \\
\hline Testosterone, $10 \mathrm{ng} / \mathrm{dl}$ increase & $0.98[0.96$ to 1$]$ & 0,097 & & \\
\hline Testosterone, $<300 \mathrm{ng} / \mathrm{dL}$ & & & $2.25[0.94$ to 5.43$]$ & 0,07 \\
\hline AUC, $[95 \%$ C.I. $]$ & $0.66[0.56$ to 0.76$]$ & & $0.66[0.57$ to 0.75$]$ & \\
\hline \multirow[t]{4}{*}{ Gain in predictive accuracy; $\%$ (p-value) } & $0.74(0.934)$ & & $1.11(0.904)$ & \\
\hline & \multicolumn{4}{|c|}{ Predominant Gleason 4} \\
\hline & Continous TT & & $\begin{array}{l}\text { TT } \geq 300 \mathrm{ng} / \mathrm{dL} \\
\text { TT }<300 \mathrm{ng} / \mathrm{dL}\end{array}$ & \\
\hline & O.R. [95\% C.I.] & $p$-value & O.R. [95\% C.I.] & $p$-value \\
\hline Age & $1[0.95$ to 1.06$]$ & 0,996 & $1[0.94$ to 1.06$]$ & 0,916 \\
\hline PSA $(\mathrm{ng} / \mathrm{mL})$ & $1.3[0.99$ to 1.71$]$ & 0,054 & $1.3[0.99$ to 1.71$]$ & 0,058 \\
\hline PSA Density, 0.1 increase & $0.16[0.05$ to 0.56$]$ & 0,004 & $0.13[0.04$ to 0.49$]$ & 0,002 \\
\hline Positive DRE & $0.86[0.32$ to 2.28$]$ & 0,755 & $0.72[0.26$ to 2.05$]$ & 0,543 \\
\hline CIPC & $1.06[1.04$ to 1.08$]$ & $<0.001$ & $1.06[1.04$ to 1.08$]$ & $<0.001$ \\
\hline Testosterone, $10 \mathrm{ng} / \mathrm{dl}$ increase & $0.96[0.93$ to 0.98$]$ & $<0.001$ & & \\
\hline Testosterone, $<300 \mathrm{ng} / \mathrm{dL}$ & & & $6.66[3.14$ to 14.15$]$ & $<0.001$ \\
\hline AUC, $[95 \%$ C.I. $]$ & $0.81[0.75$ to 0.87$]$ & & $0.82[0.75$ to 0.89$]$ & \\
\hline Gain in predictive accuracy; $\%$ (p-value) & $8.3(0.046)$ & & $9.4(0.041)$ & \\
\hline
\end{tabular}

For sake of readability of the results, when treating Testosterone as continuous predictor, the Odds Ratio have been computed for a 10ng/dl increase in TT levels. Testosterone has been analyzed both as continuous and as dichotomous predictor using 300ng/dl as cut-off. CIPC: cancer involvement in positive cores; DRE: Digital rectal examination; PNI: perineural invasion; PSA: prostate-specific antigen; TT: total testosterone

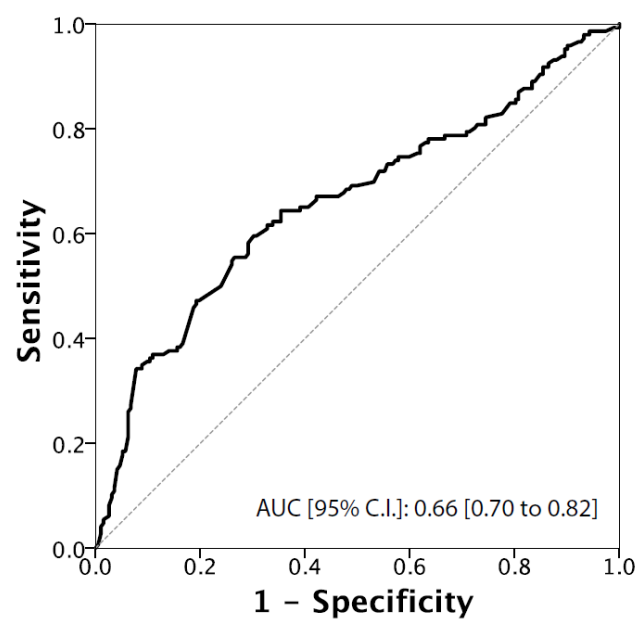

Figure 2: ROC Curve analysis for testosterone as a predictor of upgrading

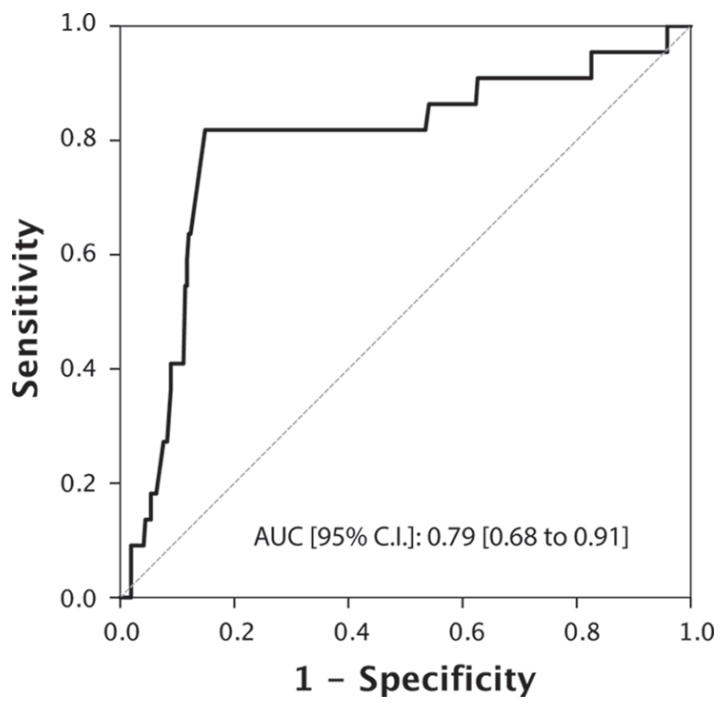

Figure 3: ROC Curve analysis for testosterone as a predictor of unfavorable disease 
treatment strategy allowing radical treatment to be delayed or avoided [19-22]. Therefore, an important focus for AS protocols is to improve the selection of patients at the time of inclusion in order to minimize the reclassification of risk during follow-up. In this context, several tools have been proposed to overcome these limitations of current AS protocols. Multiparametric magnetic resonance imaging (MRI) [23], urinary prostate cancer antigen 3 (PCA3) and serum markers [24], histopathological [25-27] and genetic factors [28-30] have been analyzed.

Little is yet known about the clinical utility of serum testosterone levels as a predictor of disease reclassification in men on AS. Recently, in a relatively small population San Francisco et al [31] showed that free, but not total testosterone levels nor the free testosterone/ total testosterone ratio or the testosterone/PSA ratio, were significantly lower in men with $\mathrm{PCa}$ and disease reclassification during AS. A number of previous reports identified a significant relationship between a high Gleason score and low testosterone levels [32-35]. Furthermore, growing evidence supports the idea that a decreased serum testosterone concentration, related to different metabolic disorders including obesity and metabolic syndrome, may modulate PCa aggressiveness [36].

We assessed the use of serum total testosterone as a predictor of disease reclassification in a cohort of men eligible for AS according to PRIAS criteria. Our results showed that men who underwent reclassification had significantly lower serum total testosterone levels compared to those who were not reclassified $(p<0.001)$. By ROC curve analysis, we identified a testosterone threshold of $344 \mathrm{ng} / \mathrm{dL}, 431 \mathrm{ng} / \mathrm{dL}, 302 \mathrm{ng} / \mathrm{dL}$ and 315 for upstaging, upgrading, unfavorable disease and predominant Gleason score 4 respectively. Men with testosterone levels lower than these values had a higher

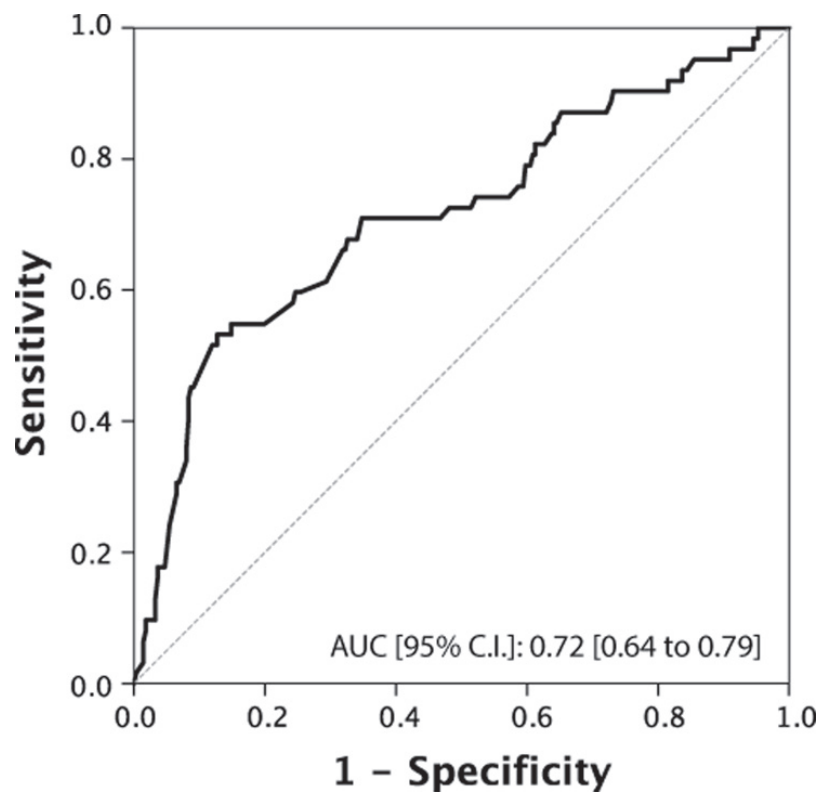

Figure 4: ROC Curve analysis for testosterone as a predictor of predominant Gleason score 4 risk of disease reclassification. When the threshold value for hypogonadism $(<300 \mathrm{ng} / \mathrm{dL})$ was used as cut-off [6, 37], we found significantly more patients with upstaging, upgrading, unfavorable disease, positive surgical margins and predominant Gleason score 4 compared to eugonadal patients. Multivariate analysis indicated that serum total testosterone, used either as a continuous or a dichotomous variable, was an independent predictor of upgrading, upstaging, unfavorable disease and predominant Gleason score 4.

Pichon et al [33] had shown in a larger study population that a low serum testosterone level was an independent predictor of a predominant Gleason pattern 4 at radical prostatectomy and of upgrading from low- to high-grade PCa between needle biopsies and prostatectomy specimens. Accordingly, the San Francisco et al study [31] showed that men on AS with low serum free testosterone levels had more than four times the risk of disease reclassification, suggesting the need for further studies to assess testosterone as a tool to better select patients for AS.

Collectively, our results suggest the importance of taking into account hypogonadism and metabolic disorders such as obesity and metabolic syndrome, as selection criteria for patients inclusion in AS programs. Consistently, the majority of large observational series have shown that obesity is a risk factor for adverse pathologic features, a more advanced stage, higher risk for biochemical recurrence after RP, and risk of death from PCa [7, 38, 39].

Our findings support the use of total testosterone as a predictor of disease reclassification for men with PCa undergoing AS. Moreover, our models including testosterone showed a significant gain in predictive accuracy of upstaging and unfavorable disease.

These data are consistent with the idea that patients with low serum testosterone levels are more likely to have aggressive PCa. AS protocols in these patients should ensure close monitoring of PSA levels and imaging examinations, in order to identify tumor progression as early as possible.

The strength of this study is the large population (338 patients on AS), allowing a robust statistical analysis. Furthermore, as recommended by the Endocrine Society guidelines, all blood samples for testosterone were analyzed using the same platform, and were collected between 07:00 AM to 10:00 AM hours, in order to avoid circadian variations and inter-assay variability. Total testosterone was measured with one of the best electrochemiluminescent immunoassays and the histological analysis of prostate biopsies and prostatectomy specimens was done by three senior uropathologists avoiding variability in Gleason scores interpretation. Moreover, exclusion criteria were strictly defined to rule out patients that had received neoadjuvant hormonal therapy or affected by other comorbidities that can affect the testosterone levels. 
However, some limitations have to be taken into account. Firstly, our study was carried out retrospectively, and several useful measures that affect testosterone values, such as Sex Hormone Binding Globulin (SHBG), luteinizing hormone and oestradiol, were not determined. In addition, like previous reports on the association between hypogonadism and a poor outcome in $\mathrm{PCa}$, we did not use mass-spectrometry-based measurements, recently advocated as the gold standard for sex steroid quantifications [40]. Finally, we lacked data about free and bioavailable testosterone, which were demonstrated to be important in a previous report [31]. The focus was primarily on the pathological findings, but we did not assess biochemical recurrence or prostate cancer-specific mortality, which might be a more important issue than the adverse pathological characteristics to better define progression. In fact, it is well accepted that disease reclassification may be the result of sampling error [41].

In conclusion, men with hypogonadism eligible for AS are at higher risk of disease upgrading and upstaging compared to men with normal serum testosterone levels. These results highlight the utility of evaluating testosterone levels in patients with localized $\mathrm{PCa}$, eligible for AS. Further prospective studies on large populations, with mass-spectrometry-based testosterone measurements and SHBG, luteinizing hormone, oestradiol, free and bioavailable testosterone data are needed to confirm our findings and support the use of circulating sex hormones as prognostic biomarkers in patients eligible for AS.

\section{MATERIALS AND METHODS}

\section{Patients}

Between January 2009 and December 2015, 338 consecutive men were referred for localized $\mathrm{PCa}$, and underwent, within 3 months of diagnosis, laparoscopic or robot-assisted laparoscopic RP at three tertiary care institutions (Departments of Urology of the National Cancer Institute "Fondazione Pascale"-Naples, of the University of Catanzaro and of the University of Bari).

Patients fulfilled the inclusion criteria for the PRIAS protocol [42] defined as: clinical stage T2a or less, PSA < $10 \mathrm{ng} / \mathrm{ml}, 2$ or less cancer involvement cores after a biopsy scheme of at least 12 cores, Gleason score $(\mathrm{GS}) \leq 6$ and PSA density $<0.2 \mathrm{ng} / \mathrm{mL} / \mathrm{cc}$.

Pathological findings in prostate biopsies were compared with pathological specimens after RP.

Reclassification was defined as disease upstaging (pathological stage $>$ pT2) and upgrading $(\mathrm{GS} \geq 7$; primary Gleason pattern 4). Unfavorable disease was defined as the occurrence of pathological stage $>$ pT2 and predominant Gleason score 4.

RP specimens were processed and evaluated according to the Stanford protocol [43] by three experienced genitourinary pathologists, blinded to the index-tests results of each Institution.

For all patients, at least 12 core biopsies were analyzed according to the 2005 International Society of Urological Pathology recommendations [44]. None of the study patients received neoadjuvant hormonal therapy (antiandrogens or luteinizing hormone-releasing hormone analogues or antagonists) or other hormonal preparations (i.e., 5- $\alpha$ reductase inhibitors) that could alter their PSA values. We also excluded patients with acute bacterial prostatitis or previous prostate surgery in the 3 months before biopsy. In addition, subjects with chronic renal disease, marked alterations in blood protein levels, hemophilia, incurable endocrine diseases or those who had previously undergone multiple transfusions, were excluded from the study because these conditions could alter the concentration of total PSA and testosterone.

Data collected included age, preoperative PSA level, PSA density, clinical stage and preoperative serum testosterone levels.

The threshold for hypogonadism was set at a total testosterone level of $300 \mathrm{ng} / \mathrm{dL}$, in agreement with the American Association of Clinical Endocrinologist guidelines [37]. Accordingly, patients were further divided into two groups: 1) low total testosterone group $(<300$ $\mathrm{ng} / \mathrm{dL}$ ) and 2) normal testosterone group ( $\geq 300 \mathrm{ng} / \mathrm{dL}$ ). Clinical stage was assessed by digital rectal examination and magnetic resonance imaging by the attending surgeon according to TNM staging (2009). Disease upstaging was regarded as pathological stage $\geq \mathrm{T} 3 \mathrm{a}$ after RP with clinical stage $\leq \mathrm{T} 2 \mathrm{c}$. Prostate cancer upgrading was defined as GS $\geq 7$ in RP specimens with GS $\leq 6$ in needle biopsies.

This study received approval from the local hospital ethics committee (i.e. institutional review board approval). Written informed consent was obtained from all patients.

\section{Hormonal assay}

All patients underwent systematic blood sampling between $7 \mathrm{AM}$ and $10 \mathrm{AM}$ on the day before surgery to assess serum total testosterone concentrations.

Electrochemiluminescence immuno-assays, using high-affinity monoclonal antibodies, were performed at the laboratories of the three Institutions, blinded to the pathological results, using Testosterone ElecsysII (Modular Analytics E170 -Roche, Basel, Switzerland).

\section{Statistical analysis}

Numerical variables were recorded and analysed as median $\left[25^{\text {th }}-75^{\text {th }}\right.$ percentile] while categorical variables were expressed as frequencies and percentages. Comparisons between groups were based on the MannWhitney or Chi square tests. The predictive accuracy of testosterone was evaluated using Receiver Operating 
Characteristic (ROC) analysis and quantified in terms of Area Under the Curve (AUC) and corresponding 95\% confidence interval (95\% C.I.). The independent role of testosterone in predicting pathological outcomes at radical prostatectomy was assessed using multivariable logistic regression models; a bootstrap approach, based on 1999 bootstrap replications, was used to compare the percentage change in predictive accuracy (in terms of AUC) between nested logistic models.

Statistical analyses and modelling were performed with R statistical computing software (R Foundation for Statistical Computing, Vienna, Austria). $P$-values $<0.05$ were considered statistically significant.

\section{ACKNOWLEDGEMENTS}

A.C. was supported by the Italian Association for Cancer Research (AIRC-MFAG number 11510).

\section{CONFLICTS OF INTEREST}

No conflicts to disclose.

\section{REFERENCES}

1. Klotz L, Zhang L, Lam A, Nam R, Mamedov A and Loblaw A. Clinical results of long-term follow-up of a large, active surveillance cohort with localized prostate cancer. J Clin Oncol. 2010; 28:126-131.

2. Klotz L. Active surveillance for prostate cancer: a review. Arch Esp Urol. 2011; 64:806-814.

3. Kim HJ, Kim BH, Park $\mathrm{CH}$ and Kim CI. Usefulness of preoperative serum testosterone as a predictor of extraprostatic extension and biochemical recurrence. Korean J Urol. 2012; 53:9-13.

4. Yamamoto S, Yonese J, Kawakami S, Ohkubo Y, Tatokoro M, Komai Y, Takeshita H, Ishikawa Y and Fukui I. Preoperative serum testosterone level as an independent predictor of treatment failure following radical prostatectomy. Eur Urol. 2007; 52:696-701.

5. Salonia A, Abdollah F, Capitanio U, Gallina A, Suardi N, Briganti A, Zanni G, Ferrari M, Castiglione F, Clementi MC, Rigatti P and Montorsi F. Preoperative sex steroids are significant predictors of early biochemical recurrence after radical prostatectomy. World J Urol. 2013; 31:275-280.

6. Xylinas E, Ploussard G, Durand X, Fabre A, Salomon L, Allory Y, Vordos D, Hoznek A, Abbou CC and de la Taille A. Low pretreatment total testosterone $(<3 \mathrm{ng} / \mathrm{mL})$ predicts extraprostatic disease in prostatectomy specimens from patients with preoperative localized prostate cancer. BJU Int. 2011; 107:1400-1403.

7. Freedland SJ, Isaacs WB, Mangold LA, Yiu SK, Grubb KA, Partin AW, Epstein JI, Walsh PC and Platz EA. Stronger association between obesity and biochemical progression after radical prostatectomy among men treated in the last
10 years. Clin Cancer Res. 2005; 11:2883-2888.

8. Iremashvili V, Soloway MS, Rosenberg DL and Manoharan M. Clinical and demographic characteristics associated with prostate cancer progression in patients on active surveillance. J Urol. 2012; 187:1594-1599.

9. Welty CJ, Cooperberg MR, Carroll PR. Meaningful end points and outcomes in men on active surveillance for earlystage prostate cancer. Curr Opin Urol. 2014 May;24:28892.

10. Lucarelli G, Rutigliano $M$, Galleggiante V, Giglio A, Palazzo S, Ferro M, Simone C, Bettocchi C, Battaglia M, Ditonno P.. Metabolomic profiling for the identification of novel diagnostic markers in prostate cancer. Expert Rev Mol Diagn. 2015;15:1211-1224.

11. Lucarelli G, Fanelli M, Larocca AM, Germinario CA, Rutigliano M, Vavallo A, Selvaggi FP, Bettocchi C, Battaglia M, Ditonno P. Serum sarcosine increases the accuracy of prostate cancer detection in patients with total serum PSA less than $4.0 \mathrm{ng} / \mathrm{ml}$. Prostate. 2012;72:16111621.

12. Lucarelli G, Rutigliano $M$, Bettocchi C, Palazzo S, Vavallo A, Galleggiante V, Trabucco S, Di Clemente D, Selvaggi FP, Battaglia M, Ditonno P. Spondin-2, a secreted extracellular matrix protein, is a novel diagnostic biomarker for prostate cancer. J Urol. 2013;190:2271-2277.

13. Ferro M, Lucarelli G, Bruzzese $\mathrm{D}$, Perdonà $\mathrm{S}$, Mazzarella $\mathrm{C}$, Perruolo G, Marino A, Cosimato V, Giorgio E, Tagliamonte V, Bottero D, De Cobelli O, Terracciano D. Improving the prediction of pathologic outcomes in patients undergoing radical prostatectomy: the value of prostate cancer antigen 3 (PCA3), prostate health index (phi) and sarcosine. Anticancer Res. 2015;35:1017-1023.

14. Cormio L, Lucarelli G, Netti GS, Stallone G, Selvaggio O, Troiano F, Di Fino G, Sanguedolce F, Bufo P, Grandaliano G, Carrieri G. Post-void residual urinary volume is an independent predictor of biopsy results in men at risk for prostate cancer. Anticancer Res. 2015 Apr;35:2175-82.

15. Cormio L, Lucarelli G, Selvaggio O, Di Fino G, Mancini V, Massenio P, Troiano F, Sanguedolce F, Bufo P, Carrieri G. Absence of Bladder Outlet Obstruction Is an Independent Risk Factor for Prostate Cancer in Men Undergoing Prostate Biopsy. Medicine (Baltimore). 2016 Feb;95:e2551.

16. Ferro M, Buonerba C, Terracciano D, Lucarelli G, Cosimato V, Bottero D, Deliu VM, Ditonno P, Perdonà S, Autorino R, Coman I, De Placido S, Di Lorenzo G, De Cobelli O.. Biomarkers in localized prostate cancer. Future Oncol. 2016 Feb;12:399-411.

17. Dall'Era MA, Albertsen PC, Bangma C, Carroll PR, Carter HB, Cooperberg MR, Freedland SJ, Klotz LH, Parker C and Soloway MS. Active surveillance for prostate cancer: a systematic review of the literature. Eur Urol. 2012; 62:976983.

18. Dinh KT, Mahal BA, Ziehr DR, Muralidhar V, Chen YW, Viswanathan VB, Nezolosky MD, Beard CJ, Choueiri TK, 
Martin NE, Orio PF, Sweeney CJ, Trinh QD and Nguyen PL. Incidence and Predictors of Upgrading and Up Staging among 10,000 Contemporary Patients with Low Risk Prostate Cancer. J Urol. 2015; 194:343-349.

19. Dall'Era MA, Cowan JE, Simko J, Shinohara K, Davies B, Konety BR, Meng MV, Perez N, Greene K and Carroll PR. Surgical management after active surveillance for low-risk prostate cancer: pathological outcomes compared with men undergoing immediate treatment. BJU Int. 2011; 107:12321237.

20. van den Bergh RC, Steyerberg EW, Khatami A, Aus G, Pihl CG, Wolters T, van Leeuwen PJ, Roobol MJ, Schroder FH and Hugosson J. Is delayed radical prostatectomy in men with low-risk screen-detected prostate cancer associated with a higher risk of unfavorable outcomes? Cancer. 2010; 116:1281-1290.

21. Shappley WV, 3rd, Kenfield SA, Kasperzyk JL, Qiu W, Stampfer MJ, Sanda MG and Chan JM. Prospective study of determinants and outcomes of deferred treatment or watchful waiting among men with prostate cancer in a nationwide cohort. J Clin Oncol. 2009; 27:4980-4985.

22. O'Brien D, Loeb S, Carvalhal GF, McGuire BB, Kan D, Hofer MD, Casey JT, Helfand BT and Catalona WJ. Delay of surgery in men with low risk prostate cancer. J Urol. 2011; 185:2143-2147.

23. de Cobelli O, Terracciano D, Tagliabue E, Raimondi S, Bottero D, Cioffi A, Jereczek-Fossa B, Petralia G, Cordima G, Almeida GL, Lucarelli G, Buonerba C, Matei DV, et al. Predicting Pathological Features at Radical Prostatectomy in Patients with Prostate Cancer Eligible for Active Surveillance by Multiparametric Magnetic Resonance Imaging. PLoS One. 2015 Oct 7;10:e0139696.

24. Cantiello F, Russo GI, Cicione A, Ferro M, Cimino S, Favilla V, Perdona S, De Cobelli O, Magno C, Morgia G and Damiano R. PHI and PCA3 improve the prognostic performance of PRIAS and Epstein criteria in predicting insignificant prostate cancer in men eligible for active surveillance. World J Urol. 2016; 34:485-493.

25. Gofrit ON, Zorn KC, Taxy JB, Lin S, Zagaja GP, Steinberg GD and Shalhav AL. Predicting the risk of patients with biopsy Gleason score 6 to harbor a higher grade cancer. J Urol. 2007; 178:1925-1928.

26. Moon SJ, Park SY and Lee TY. Predictive factors of Gleason score upgrading in localized and locally advanced prostate cancer diagnosed by prostate biopsy. Korean J Urol. 2010; 51:677-682.

27. Stav K, Judith S, Merald H, Leibovici D, Lindner A and Zisman A. Does prostate biopsy Gleason score accurately express the biologic features of prostate cancer? Urol Oncol. 2007; 25:383-386.

28. Klein EA. A genomic approach to active surveillance: a step toward precision medicine. Asian J Androl. 2013; 15:340341.

29. Cuzick J, Yang ZH, Fisher G, Tikishvili E, Stone S,
Lanchbury JS, Camacho N, Merson S, Brewer D, Cooper CS, Clark J, Berney DM, Moller H, et al. Prognostic value of PTEN loss in men with conservatively managed localised prostate cancer. Br J Cancer. 2013; 108:2582-2589.

30. Grossi V, Lucarelli G, Forte G, Peserico A, Matrone A, Germani A, Rutigliano M, Stella A, Bagnulo R, Loconte D, Galleggiante V, Sanguedolce F, Cagiano S, et al. Loss of STK11 expression is an early event in prostate carcinogenesis and predicts therapeutic response to targeted therapy against MAPK/p38. Autophagy. $2015 \mathrm{Nov}$ 2;11:2102-2113.

31. San Francisco IF, Rojas PA, DeWolf WC and Morgentaler A. Low free testosterone levels predict disease reclassification in men with prostate cancer undergoing active surveillance. BJU Int. 2014; 114:229-235.

32. Dai B, Qu Y, Kong Y, Ye D, Yao X, Zhang S, Wang $\mathrm{C}$, Zhang $\mathrm{H}$ and Yang W. Low pretreatment serum total testosterone is associated with a high incidence of Gleason score 8-10 disease in prostatectomy specimens: data from ethnic Chinese patients with localized prostate cancer. BJU Int. 2012; 110:E667-672.

33. Pichon A, Neuzillet Y, Botto H, Raynaud JP, Radulescu C, Molinie V, Herve JM and Lebret T. Preoperative low serum testosterone is associated with high-grade prostate cancer and an increased Gleason score upgrading. Prostate Cancer Prostatic Dis. 2015; 18:382-387.

34. Gao Y, Jiang CY, Mao SK, Cui D, Hao KY, Zhao W, Jiang Q, Ruan Y, Xia SJ and Han BM. Low serum testosterone predicts upgrading and upstaging of prostate cancer after radical prostatectomy. Asian J Androl. 2016.

35. Leon $\mathrm{P}$, Seisen $\mathrm{T}$, Cussenot $\mathrm{O}$, Drouin SJ, Cattarino S, Comperat E, Renard-Penna R, Mozer P, Bitker MO and Roupret M. Low circulating free and bioavailable testosterone levels as predictors of high-grade tumors in patients undergoing radical prostatectomy for localized prostate cancer. Urol Oncol. 2015; 33:384 e321-387.

36. Bhindi B, Locke J, Alibhai SM, Kulkarni GS, Margel DS, Hamilton RJ, Finelli A, Trachtenberg J, Zlotta AR, Toi A, Hersey KM, Evans A, van der Kwast TH and Fleshner NE. Dissecting the association between metabolic syndrome and prostate cancer risk: analysis of a large clinical cohort. Eur Urol. 2015; 67:64-70.

37. Petak SM, Nankin HR, Spark RF, Swerdloff RS and Rodriguez-Rigau LJ. American Association of Clinical Endocrinologists Medical Guidelines for clinical practice for the evaluation and treatment of hypogonadism in adult male patients - 2002 update. Endocr Pract. 2002; 8:440456.

38. Kane CJ, Bassett WW, Sadetsky N, Silva S, Wallace K, Pasta DJ, Cooperberg MR, Chan JM and Carroll PR. Obesity and prostate cancer clinical risk factors at presentation: data from CaPSURE. J Urol. 2005; 173:732736.

39. Amling CL, Kane CJ, Riffenburgh RH, Ward JF, Roberts JL, Lance RS, Friedrichs PA and Moul JW. Relationship 
between obesity and race in predicting adverse pathologic variables in patients undergoing radical prostatectomy. Urology. 2001; 58:723-728.

40. Handelsman DJ and Wartofsky L. Requirement for mass spectrometry sex steroid assays in the Journal of Clinical Endocrinology and Metabolism. J Clin Endocrinol Metab. 2013; 98:3971-3973.

41. Shapiro RH and Johnstone PA. Risk of Gleason grade inaccuracies in prostate cancer patients eligible for active surveillance. Urology. 2012; 80:661-666.

42. Bangma $\mathrm{CH}, \mathrm{Bul} \mathrm{M}$ and Roobol M. The Prostate cancer Research International: Active Surveillance study. Curr Opin Urol. 2012; 22:216-221.

43. van der Kwast TH, Amin MB, Billis A, Epstein JI, Griffiths D, Humphrey PA, Montironi R, Wheeler TM, Srigley JR, Egevad L and Delahunt B. International Society of
Urological Pathology (ISUP) Consensus Conference on Handling and Staging of Radical Prostatectomy Specimens. Working group 2: T2 substaging and prostate cancer volume. Mod Pathol. 2011; 24:16-25.

44. Epstein JI, Allsbrook WC, Jr., Amin MB and Egevad LL. The 2005 International Society of Urological Pathology (ISUP) Consensus Conference on Gleason Grading of Prostatic Carcinoma. Am J Surg Pathol. 2005; 29:12281242. 